Gmelins Handbuch der anorganischen Chemie Achte völlig neu bearbeitete Auflage. Herausgegeben von der Deutschen Chemischen Gesellschaft. System-Nummer 59 : Eisen. Teil F II, Lieferung 2 : Nachweis und Bestimmung von Fremdelementen in Eisen und Stahl. Pp. xvi $+165+388.27$ gold marks. (2) System-Nummer 59 : Eisen. Teil C, Lieferung 2 : Prüfung der Kerbschlagzähigkeit. Pp. viii +288 . 33 gold marks. (Berlin : Verlag Chemie, G.m.b.H., 1939.)

(1) A FTER dealing in full detail with all the commoner analytical methods for the detection and estimation of titanium, aluminium, cerium, thorium, nickel and cobalt in iron and steel, the application of more modern methods is described in the part of "Gmelins Handbuch" under notice. Although no details are as yet available in the literature for the use of the chromatographic adsorption method of analysis, which has hitherto been used almost exclusively with organic compounds, its application by Schwab to the analysis of steels appears to be so promising that details of the process are given much more fully than might have been expected. Results which have been obtained with Heyróvskýs polarographic method of using a dropping mercury cathode and a large mercury anode with gradually increasing voltage have shown that, after removal of the iron from the solution, an extremely sensitive and rapid method of qualitative and quantitative analysis of other elements is available. Photographic records can be obtained, but where speed is required they may be replaced by visible readings on a mirror-galvanometer scale. Perhaps the most sensitive method of all for qualitative analysis is that of spectrum analysis, which is fully described. Standard methods adopted by Australia, Canada, France, Italy, Japan, the U.S.S.R. and the United States are tabulated at the end. No standard methods have been adopted by Germany, and Great Britain is not mentioned.

(2) The extraordinary thoroughness with which the editors of "Gmelins Handbuch" are dealing with the metal iron is clearly shown by the issue of several highly specialized sections, of which this, which deals only with the notched-bar impact test for the toughness of iron and steels, is a sample. The chemist will find little of immediate interest, but the numerous drawings of machines, photographs of actual tests, graphs of physical properties and tables of reference to original papers should make it a valuable work of reference to engineers and metallurgists.

Chemische Physik der Metalle und Legierungen Von Prof. Ulrich Dehlinger. (Physik und Chemie und ihre Anwendungen in Einzeldarstellungen, Band 3.) Pp. xi+174. (Leipzig: Akademische Verlagsgesellschaft m.b.H., 1939.) 12 gold marks.

MUCH exact experimental work has been carried NI out in recent years on metals and their alloys, and the knowledge of transformations of the crystal lattice, such as occur in plastic deformation, in the separation of a new phase, or in the change from a disordered to an ordered structure, has been greatly advanced. Progress has also been mado in the description of the metallic state in terms of quantum mechanics. The stage has not yet been reached, however, at which the chief properties of a metal or alloy after a given treatment can be arrived at by deduction.

The work of Dehlinger, himself an active investigator in this field, aims at interpreting the relations between experiment and theory, especially for the benefit of the metallurgist. He treats of the thermodynamies of phase equilibria, with the distribution of electrons among the atoms, leading to the HumeRothery and similar rules, with the various types of structure among alloys, and with ferromagnetism. The last portion of the book deals with the kinetic aspects, such as diffusion, allotropic change, and precipitation of a new phase from solid solution. Plasticity and the mosaic structure of metallic crystals are only touched upon. Perhaps the most interesting sections are those which deal with the different forms of precipitation, including age-hardening. The book was probably completed too soon to include the important discoveries of Preston and Guinier on the nature of the initial stages of precipitation. Although German work receives most attention, an effort has evidently been made to cover the literature, and there is a useful bibliography.

C. H. D.

\section{British Blood-Sucking Flies}

By Dr. F. W. Edwards, H. Oldroyd and Dr. J. Smart. Pp. viii $+156+45$ plates. (London : British Museum (Natural History), 1939.) $15 s$.

THE predecessor of this book entitled "Illustrations of British Blood-Sucking Flies" was written by the late E. E. Austen and published in 1906. Within a few years the edition was exhausted, and it evidently filled a definite need. Its successor is a larger and more informative work the aim of which is similar, and that is to provide information of interest to the non-specialist in the simplest possible manner. Increase in knowledge of blood-sucking flies since the 1906 volume has been great. Thus, in that year about 2700 species of British flies are stated to have been known, including 74 that are actually, or potentially, blood-suckers. In the intervening thirtytwo years these figures have increased to 5,200 and 117 respectively. Much more important than mere additions of species is the notable increase in knowledge of their life-cycles and behaviour.

This volume deserves all praise : it gives the right kind of information required by the non-specialist and avoids irrelevant detail. The accounts of the species are supplemented by 45 excellent three-colour process plates. If a new edition of this work be called for, the practical aspect of the subject might receive more detailed consideration. A short section on the treatment of mosquito and other insect 'bites' by alleviatory measures or by repellents need not occupy much space but would be welcomed. We hope that the Trustees of the Museum will bear in mind the importance of issuing works, like the present one, of more general interest as well as those that only appeal to a small coterie of specialists and, sometimes, very few of them British subjects.

A. D. I. 